\title{
Nuclear Peroxisome Proliferator-Activated Receptors (PPARs) as Therapeutic Targets of Resveratrol for Autism Spectrum Disorder
}

\author{
Rita Barone ${ }^{1,2,3, *,+}$, Renata Rizzo ${ }^{1,+}$, Giovanni Tabbì ${ }^{4}$, Michele Malaguarnera ${ }^{5,6}{ }^{(D)}$, \\ Richard E. Frye ${ }^{7,8}$ and Jean Bastin $9,10,11,12,13$ \\ 1 Child Neurology and Psychiatry Unit, Department of Clinical and Experimental Medicine, \\ University of Catania, 95123 Catania, Italy; rerizzo@unict.it \\ 2 Referral Centre for Inborn Metabolic Diseases, Department of Clinical and Experimental Medicine, \\ University of Catania, 95123 Catania, Italy \\ 3 Institute for Polymers, Composites and Biomaterials (IPCB), National Research Council (CNR), \\ 95126 Catania, Italy \\ 4 Institute of Crystallography (IC), National Research Council (CNR), 95126 Catania, Italy; \\ giovanni.tabbi@cnr.it \\ 5 Laboratory of Neurobiology, Centro Investigación Príncipe Felipe, 46012 Valencia, Spain; \\ michele.malaguarnera@gmail.com \\ 6 Research Center "The Great Senescence", University of Catania, 95123 Catania, Italy \\ 7 Barrow Neurologic Institute at Phoenix Children's Hospital, Phoenix, AZ 85016, USA; \\ rfrye@phoenixchildrens.com \\ 8 Department of Child Health, University of Arizona College of Medicine, Phoenix, AZ 85016, USA \\ 9 Centre de Recherche des Cordeliers, 75006 Paris, France; jean.bastin@inserm.fr \\ 10 Sorbonne Université, USPC, 75006 Paris, France \\ 11 Université Paris Descartes, 75006 Paris, France \\ 12 Université Paris Diderot, 75006 Paris, France \\ 13 INSERM UMR-S 1138, 75006 Paris, France \\ * Correspondence: rbarone@unict.it \\ + These authors contributed equally to this work.
}

Received: 22 February 2019; Accepted: 12 April 2019; Published: 16 April 2019

\begin{abstract}
Autism spectrum disorder (ASD) is a neurodevelopmental disorder characterized by defective social communication and interaction and restricted, repetitive behavior with a complex, multifactorial etiology. Despite an increasing worldwide prevalence of ASD, there is currently no pharmacological cure to treat core symptoms of ASD. Clinical evidence and molecular data support the role of impaired mitochondrial fatty acid oxidation (FAO) in ASD. The recognition of defects in energy metabolism in ASD may be important for better understanding ASD and developing therapeutic intervention. The nuclear peroxisome proliferator-activated receptors (PPAR) $\alpha, \delta$, and $\gamma$ are ligand-activated receptors with distinct physiological functions in regulating lipid and glucose metabolism, as well as inflammatory response. PPAR activation allows a coordinated up-regulation of numerous FAO enzymes, resulting in significant PPAR-driven increases in mitochondrial FAO flux. Resveratrol (RSV) is a polyphenolic compound which exhibits metabolic, antioxidant, and anti-inflammatory properties, pointing to possible applications in ASD therapeutics. In this study, we review the evidence for the existing links between ASD and impaired mitochondrial FAO and review the potential implications for regulation of mitochondrial FAO in ASD by PPAR activators, including RSV.
\end{abstract}

Keywords: autism spectrum disorders; mitochondrial fatty acid $\beta$-oxidation metabolism; PPARs agonists; resveratrol 


\section{Introduction}

Autism spectrum disorder (ASD) is a lifelong condition characterized by persistent deficits in social communication and social interaction across multiple contexts and restricted and/or repetitive patterns of behavior and/or activities that must be present in the early developmental period [1]. ASD affect males more than females by a ratio of $4: 1$. The current prevalence is estimated to be one in 59 children aged 8 years of age in the US [2]. The precise etiology remains unknown although various factors are involved including genetic factors, environmental toxins and stressors, impaired immune responses, mitochondrial dysfunction, and neuroinflammation [3].

Classic inborn errors of metabolism (IEM) are monogenic diseases that affect a subgroup of ASD patients, accounting for 1-3\% of children with ASD [4-6]. Among genetic metabolic diseases, primary mitochondrial diseases (MD) affect the structure or function of the mitochondria, because of either nuclear DNA (nDNA), or mitochondrial DNA (mtDNA) mutations [7]. MD are heterogeneous disorders with complex, poorly understood pathogenesis. Very diverse phenotypes are encountered in $\mathrm{MD}$, possibly affecting numerous organs, and frequently involving the central nervous system (CNS). Mitochondrial bioenergetic defects have been associated with ASD because the brain is one of the most energy-dependent tissues in the body. Impaired mitochondrial metabolism may influence neuronal development and synaptic plasticity, which are crucial processes for neurodevelopment and contribute to ASD.

Meta-analyses on three case-series including 536 patients with ASD showed 5\% of overall prevalence of primary MD in ASD. However, almost 30\% of children with idiopathic ASD have an increase of lactic acid in plasma with respect to normal reference values [8]. In addition, markers of mitochondrial dysfunctions have been identified in peripheral tissues such as skeletal muscle [9], blood leukocytes [10,11], buccal mucosa [12], and in the brain of ASD patients by in vivo magnetic resonance spectroscopy [13]. On a clinical ground, children with idiopathic ASD may exhibit features of a MD, such as modified rate of head circumference growth, seizures, motor delay, gastrointestinal disturbances, and regression following fever or other environmental inputs $[8,9]$.

Mitochondrial long-chain fatty acid (LCFA) oxidation (mtFAO) is an important source of energy production in mammals. LCFAs require the carnitine-mediated translocation of long-chain acyl-CoAs from cytoplasm into mitochondria where $\beta$-oxidation takes place. $\beta$-oxidation is characterized by repeated cycles of sequential shortening of the fatty acid by two carbons via four enzymatic steps with production of one acetyl-CoA during each cycle. The adult diet mostly provides LCFAs and very low amounts of medium- or short-chain fatty acids, which can also undergo $\beta$-oxidized in the mitochondria. Inborn carnitine defects or mtFAO defects induce energy deficiencies and other complex pathogenic states affecting many tissues including brain, liver, heart, and skeletal muscle [14-17].

ASD and ASD-type behavior have been described in patients with genetic defects of mtFAO $[18,19]$. Likewise, biomarkers of impaired mtFAO, such as depressed free carnitine levels and an increase of long-chain acyl-carnitine species, have been identified in patients with idiopathic ASD [20,21]. A full knowledge of mtFAO metabolism in the patho-physiology of ASD is still missing, however, the recognition of deficits in energy metabolism in patients with ASD may be important for better understanding the underlying biological abnormalities and, in turn, therapeutic interventions.

Nuclear peroxisome proliferator-activated receptors (PPAR) are ligand-activated receptors with distinct physiological functions and tissue distribution. Three PPAR isoforms, $\alpha, \delta$, and $\gamma$, have been described, which differ in their target genes, physiological functions, and tissue distribution [22,23]. $\operatorname{PPAR} \alpha$ and $\delta$ are preferentially involved in the control of $\beta$-oxidation in organs with high energy demands like the heart, skeletal muscle, liver, or kidneys [24-28], whereas PPAR $\gamma$ is highly expressed in peripheral tissues with high fatty acid synthesis and storage, such as adipose tissue [23,29]. Various studies document the presence of the three PPARs isoforms in neurons and glial brain cells, and support the role of these nuclear receptors in neuroprotection [29,30]. Recent evidence suggests the effectiveness of PPAR $\alpha$ activation in amelioration of core symptoms in ASD rodent models [31]. Moreover, the PPAR $\gamma$ agonist pioglitazone has been used in clinical trials suggesting that PPARs might be targets for 
drug therapy of ASD [32,33]. Resveratrol (RSV) is polyphenolic compound, considered as a natural PPARs agonist [34,35], and is present at high levels in red grapes, nuts, pomegranates, and in the Japanese knotgrass (Polygonum cuspidatum). RSV has metabolic, antioxidant, and anti-inflammatory activities as well as neuroprotective effects [36-39], and its therapeutic potential has been evaluated in animal models and in humans in a wide spectrum of pathologies [40,41]. All of these biological activities may have possible applications and points of interest in ASD therapeutics, although only a few studies have been reported concerning their potential effect on ASD treatment [42-46].

In this study, we introduce the existing links between ASD and impaired mtFAO and review the potential implications for regulation of mtFAO in ASD by PPAR activators, including RSV.

\section{Autism Spectrum Disorder in Genetic Diseases of Mitochondrial Fatty Acid $\beta$-Oxidation}

mtFAO represents a major source of ATP in various tissues with high energy demand, in particular the heart, skeletal muscle, and liver, particularly when fasting or prolonged exercise requires glucose sparing. In these situations, adipose tissue lipolysis makes free fatty acids available for mitochondrial $\beta$-oxidation, providing acetyl-CoA that enters the tricarboxylic acid (TCA) cycle for complete oxidation. Overall, the re-oxidation of $\mathrm{NADH}$ and $\mathrm{FADH}_{2}$ produced by these processes allows large amounts of ATP production by the respiratory chain, making LCFA high-yielding energy substrates. Hepatic $\beta$-oxidation also provides acetyl-CoA for production of ketone bodies, which are used as "glucose sparing" energy substrates by the brain during fasting [16]. In addition to these bioenergetic functions, recent studies suggest that mtFAO plays a key role in providing acetyl-CoA for posttranslational modifications of cellular proteins by lysine acetylation. This process affects not only the mitochondrial compartment, in which a large number of metabolic enzymes exist in acetylated/deacetylated form [47], but also the nucleus, in which acetyl-CoA derived from mtFAO can be used as a substrate for acetylation of transcription factors and transcription co-activators, but also, importantly, of histones $[48,49]$. Thus, carbons stemming from fatty acids integrate into the epigenome by histone acetylation, and it is known that increases in histone acetylation are associated with chromatin relaxation, facilitated access of transcription factors, and activation of gene expression. Accordingly, this epigenetic regulation of gene expression establishes a functional link between energy metabolism, chromatin status, and gene expression [50]. How genetic and environmental heterogeneity affect specific molecular pathways in individuals with ASD is not well understood. It has been proposed that epigenetic changes driven by genetics and environmental stressors may negatively influence biological pathways important for brain development. Methylation changes have been found in several ASD candidate genes, such as the gene encoding the oxytocin receptor (OXTR) as well as RELN and SHANK3 genes. Moreover, changes in DNA methylation have been confirmed in studies aimed at directly defining ASD-specific epigenetics patterns [51]. Recently, a histone acetylome-wide association analyses was conducted on postmortem ASD brain samples and matched control brains. The study showed aberrations in histone acetylation in the prefrontal and temporal cortex of patients with ASD. It is noteworthy that the aforementioned epigenetic modifications were found to affect genes related to ion channels, synaptic function, and epilepsy/neuronal excitability, all of which have previously been shown to be dysregulated in ASD [52].

More than fifteen inborn errors of mtFAO have been described so far [16], which are caused by the deficiency of a single mitochondrial enzyme in the $\beta$-oxidation pathway. Briefly, the mtFAO defects mainly affect one of the components of the LCFA import shuttle, or one of the acyl-CoA dehydrogenase isoforms, such as short chain acyl-CoA dehydrogenase (SCAD), medium chain acyl-CoA dehydrogenase (MCAD), very long chain acyl-CoA dehydrogenase (VLCAD), or the mitochondrial trifunctional protein [long chain 3-hydroxyacyl-CoA dehydrogenase (LCHAD)] [16,17]. Mitochondrial $\beta$-oxidation deficiencies may also be secondary to defects of dedicated processes, for example, due to mutations in the carnitine transporter genes, or due to deficiencies in the mitochondrial electron transfer flavoprotein system (multiple acyl-CoA dehydrogenase deficiency) $[14,16]$. Molecular studies have revealed a great variety of gene mutations associated with inborn errors of $\mathrm{mtFAO}$, all transmitted as autosomal recessive traits in humans. Clinically, FAO disorders present with overlapping features such as 
hypotonia, muscle weakness, cardiomyopathy, liver failure, encephalopathy, seizures, developmental delay/regression, and behavioral problems. Clinical presentation is highly variable, ranging from severe neonatal forms with sudden death or life-threatening multi-organ failure (Reye-like syndrome), up to mild adult-onset phenotypes [14,15].

ASD and ASD-type behavior have been reported in patients with genetic defects of mtFAO, such as VLCAD deficiency [18]. ASD is the main neuropsychiatric feature of patients with deficiency of the LCHAD enzyme, which has a high specificity for the degradation of fatty acids with 12-16 carbon chain lengths. It has been hypothesized that in VLCAD and in LCHAD deficiency, energy defects and accumulation of unmetabolized intermediates might have a particular detrimental effect on the brain during development and in adults $[19,53]$.

Deletion of the TMLHE gene, which is part of the carnitine synthesis pathway and located on the $\mathrm{X}$ chromosome, is found more often in male-male multiplex families with non-dysmorphic autism, suggesting that TMLHE deficiency is a risk factor for ASD, albeit with low penetrance (estimated at 2-4\%) [54]. As a whole, the occurrence of ASD-like behavior or ASD in genetic defects of carnitine biosynthesis and mitochondrial $\beta$-oxidation supports the role of dysfunctional mitochondrial $\beta$-oxidation as a possible mechanism underlying ASD, at least in a patient subset.

\section{Fatty Acids in the Energy Metabolism of the Central Nervous System in Autism Spectrum Disorder}

It is often assumed that the adult brain does not oxidize fatty acids, since neurons mainly use glucose and lactate for energy production $[55,56]$. However, fatty acids can enter the brain and be oxidized in astrocytes [56], and they likely represent an important oxidative fuel during embryonic and early postnatal development in rodent neural cells [56,57]. The carnitine palmitoyl transferase (CPT) system, which mediates the entry of LCFAs into the mitochondria for $\beta$-oxidation, is expressed in astrocytes [56,57], and in embryonic [58] and adult [59] neural stem cells (NSC). Recent data in mice indicate that pharmacological inhibition or conditional deletion of the CPT system alters NSC homeostasis in the embryonic and adult brain as well, suggesting that FAO might have an instructive role in neural cell differentiation [59]. In line with this, it is noteworthy that neuronal migration defects and brain dysgenesis have been described in human fetuses with the most severe presentation of inborn Carnitine Palmitoyl Transferase 2 (CPT2) deficiency [60], and in other genetic mtFAO disorders [61]. Accordingly, alterations in NSC homeostasis might account for the link between FAO defects and neurodevelopmental diseases such as ASD [57-59].

\section{Evidence of Dysfunctional Mitochondrial Fatty Acid $\beta$-Oxidation in Patients with Idiopathic Autism}

In patients with idiopathic ASD [62], as well as in patients with genetic defects of mtFAO [63], developmental plateau and/or neurological regression triggered by metabolic stress (fasting), or by immune activation such as fever and infections, may follow a period of initially normal infant development. Actually, mitochondrial dysfunction may ensue during a period of metabolic stress (fasting), inducing catabolism, or as a result of immune activation, inducing inflammatory response and high rates of ATP consumption. Likewise, symptoms of mtFAO deficiencies can be provoked or aggravated by energy-requiring states such as fasting, infection, or a combination of both. For example, during starvation, reduced energy supply to the liver will ultimately result in hyperammonemia potentially responsible for brain edema, encephalopathy, and Reye-like syndrome [14-17]. Encephalopathy with high fever and severe brain damage can also be observed in influenza-infected patients harboring DNA variants of the CPT2 gene [64].

Metabolic abnormalities that occur in genetic defects of mtFAO are also seen in patients with ASD and include low plasma free carnitine levels and increase of saturated and unsaturated long-chain acyl-carnitines species, as well as hyperammonemia, abnormal plasma amino acid levels and elevated urinary excretion of TCA metabolites and dicarboxylic acids $[8,20,21]$. 
Previous clinical studies showed the existence, in subsets of patients with ASD, of elevated blood fatty acids, particularly LCFAs and very LCFAs $[20,65,66]$. Accumulation of LCFAs or their CoA or carnitine esters primarily inhibits energy metabolism at various steps, such as fatty acid synthesis, TCA cycle functioning, glutamate metabolism, and oxidative phosphorylation or secondarily by inducing carnitine, and coenzyme A or fatty acid binding protein depletion $[67,68]$.

Furthermore, patients with ASD show a unique plasma acyl-carnitine profile with an increase in unmetabolized long-chain and short-chain acyl-carnitines [20,69]. We recently investigated an easily testable blood metabolic profile, including acyl-carnitines and amino acids, using high throughput analyses of samples extracted from dried blood spots (DBS). Out of 45 analyzed metabolites, nine (20\%) were significantly increased in ASD patients, including the amino acid citrulline and acyl-carnitines $\mathrm{C} 2$, $\mathrm{C} 4 \mathrm{DC} / \mathrm{C} 5 \mathrm{OH}, \mathrm{C} 10, \mathrm{C} 12, \mathrm{C} 14: 2, \mathrm{C} 16, \mathrm{C} 16: 1$, and C18:1 $(P<0.001)$. By a naïve Bayes algorithm, we found an increased performance of the algorithm based on the identified acyl-carnitines for classifying ASD in toddlers ( $n$ : 42 subjects; mean age $3.26 \pm 0.89)$ with $72.3 \%$ sensitivity (95\% CI: $71.3 ; 73.9), 72.1 \%$ specificity (95\% CI: 71.2;72.9), and diagnostic odds ratio (DOR) of 11.25 (95\% CI: 9.47;17.74). Considering the heterogeneity of ASD, we suggest that metabolic profiling may support the identification of phenotypes, enabling individualized therapeutic approaches in children at risk of developing the disease [70]. ESI-MS/MS analyses of different metabolites in DBS represent a high throughput method for metabolic profiling of individuals with ASD by a single injection, in a rapid, low-cost, and suitable procedure. Moreover, DBS-MS application has inherent advantages, such as collecting a small sample volume that is easily transported. However, it should be noted that several parameters can impact the accuracy of DBS measurement. In particular, robust, independent reference intervals for DBS analytes should be established [71].

The role of dysfunctional mtFAO in autism is supported by the observation that intracerebral or systemic administration of propionic acid (PPA) to adult rats induces repetitive movements, hyperactive behavior, and seizure activity, consistent with the rodent ASD model known as the PPA model [72]. In the PPA model, the induced ASD behavior is associated with the increase of total, long-chain, and short-chain acyl-carnitines in brain tissue. Thus, the rodent PPA model of ASD suggests a link between an abnormal acyl-carnitine profile in the brain and ASD behavior [73].

Physiologically, endogenous PPA acid derives from the catabolism of branched-chain amino acids and from odd-chain fatty acid catabolism. Moreover, PPA, along with short chain fatty acids such as acetate and butyrate, are major metabolic products of enteric bacteria enriched in stool samples of patients with ASD, and have been shown to modulate mitochondrial function in cell lines from patients with ASD [73-75]. PPA accumulation is toxic for the CNS by interfering with cellular metabolism and cell-to-cell communication and increasing inflammatory response [75]. In humans, detrimental effects of PPA accumulation are dramatically illustrated by propionic acidemia (PA). PA is a severe organic acidemia caused by a defect of propionyl-CoA carboxylase and PPA accumulation in body fluids and tissues. Patients with PA have neurological impairment and ASD or ASD behavior [76].

To summarize, the acyl-carnitines profile observed in subsets of ASD patients and in PPA rodent ASD model support the hypothesis of a partial mtFAO deficiency, but it appears relatively atypical compared to the profiles observed in inborn monogenic disorders affecting one of the enzymes in the mtFAO pathway. However, partial defects in the activity of several enzymes in the mtFAO pathway might lead to relatively unspecific acyl-carnitine accumulation. Furthermore, partial defects in mtFAO can also be related to respiratory chain $(\mathrm{RC})$ dysfunction, since there are strong functional links between the mIFAO and RC pathways and increasing evidence shows that mitochondrial dysfunction associated with ASD includes deficient activity levels of both the mitochondrial RC and FAO pathways [77,78].

\section{Molecular Regulation of Mitochondrial FAO: The PPAR Pathway}

It is presently assumed that partial defects in mitochondrial functions might be a determining factor in the pathophysiology of ASD and other neuropsychiatric disorders $[8,79,80]$. In line with this, it can be thought that some of these disorders may be treatable by means of bioenergetic 
interventions [78-80]. The activity of mitochondrial energy producing pathways, and in particular of $\mathrm{mtFAO}$, is regulated by way of changes in the transcription of genes encoding the various enzymes in these pathways. The PPAR $\alpha, \delta$, and $\gamma$ are ligand-activated receptors that bind a variety of endogenous LCFAs or their derivatives (prostaglandin, leukotrienes) [23]. Upon activation by these natural ligands, PPARs bind specific recognition sequences, called PPAR-response elements, in the promoter regions of target genes, leading to marked up-regulation of gene transcription $[25,29,81]$. The resulting increases in mRNA abundance translate into increased proteins and enzyme activity, and allow the coordinated up-regulation of numerous mtFAO enzymes, resulting in significant PPAR-driven increases in the mtFAO flux [24,26,29]. An additional important regulator of mtFAO is the transcription co-activator PGC1- $\alpha$. This co-activator acts as a recruiting platform to bind and activate a number of transcription factors, including the PPARs, and, accordingly, mediates a variety of stimulatory effects on mitochondrial bioenergetics across multiple organs, including the brain $[82,83]$. The PGC1- $\alpha$ mediates transcriptional co-activation by phosphorylating or methylating histones, remodeling chromatin, and recruiting RNA polymerase [81]. Importantly, the expression of the PGC1- $\alpha$ gene can vary in response to physiological or metabolic stress conditions (i.e., exercise, starvation), is positively regulated by the PPARs, and represents a master regulator of mitochondrial functions under physiological conditions, and in a variety of neurological, metabolic, or aging diseases [82-84].

\subsection{PPARs Activators for Treatment of Mitochondrial FAO Defects}

PPAR receptors have attracted much attention, due to the existence of various synthetic activators, some of which are commonly prescribed drugs in human medicine. Indeed, fibrates (activators of PPAR $\alpha$ and beta- $\delta$ ) and thiazolidinediones (TZD; PPAR $\gamma$ ligands) are used for the treatment of dyslipidemia and diabetes, respectively $[25,26,85]$. There are also consistent data showing that genetic mtFAO defects, including CPT2 [86] and the VLCAD deficiency [87], can be corrected in fibroblasts from affected patients after treatment with bezafibrate. Thus, exposure to bezafibrate up-regulates CPT2 and VLCAD proteins and enzyme activities, and induces a coordinated increase in the proteins and enzyme activities of respiratory chain complexes I to V in human fibroblasts $[15,88]$. Interestingly, CPT2-, VLCAD-, or glutaric acidemia type II - deficient fibroblasts exhibit specific patterns of acyl-carnitines accumulation, which are normalized following cell treatment by bezafibrate $[15,89,90]$. In line with this, an open label trial in six patients with inborn defects in CPT2 showed that bezafibrate treatment stimulated long-chain FAO in the skeletal muscle, improved physical activity, and reduced the myopathic manifestations of the disease [91,92]. Bezafibrate is also presently tested in adults with a mitochondrial myopathy [93], on the basis of ex vivo observations showing that bezafibrate can restore inborn respiratory chain defects by stimulating the expression of deficient protein and mitochondrial biogenesis [88]. Besides inborn deficiencies of FAO, it was shown that bezafibrate upregulates CPT2 and energy metabolism in fibroblasts of patients with influenza-associated encephalopathy (IAE) [64,94]. IAE is particularly frequent is east Asians and is characterized by high fever following viral infections, severe brain damage, and multi-organ failure, with high rate of mortality and disability. IAE has been associated with a thermolabile CPT2 enzyme phenotype, and, at the molecular level, with the CPT2, F352C, and F352C+V368I gene variants. The bezafibrate-induced transcriptional upregulation of CPT2 and amelioration of cellular ATP levels in fibroblasts from patients with IAE at $37^{\circ} \mathrm{C}$ and even at $41^{\circ} \mathrm{C}$ suggests possible therapeutic use in patients with IAE [64].

\subsection{PPARs and Neuropsychiatric Diseases}

Various studies document the presence of the three PPAR isoforms in CNS neurons and glial cells, and support the role of these nuclear receptors in cognition and behavior [30,83]. In this regard, a transplacental influence of the maternal PPAR $\gamma$ variants on human fetal brain development has been demonstrated. Offspring from mothers bearing the wild allele outscore those of mother with the polymorphic Pro12Ala in cognitive, language, and motor development at the age of 18 months [95]. Several drugs of the fibrate group widely prescribed as hypolipidemic drugs, including bezafibrate, 
fenofibrate, gemfibrozil, and ciprofibrate, are activators of the PPARs, although they do not activate all PPAR isoforms equally [22]. Numerous studies in rodents have shown that administration of PPAR agonists up-regulated gene expression levels, resulting in greater levels of enzymes and proteins of mitochondrial oxidative metabolism, and stimulated mitochondrial biogenesis in various tissues [96,97]. Pharmacological activation of PPARs is also known to increase the expression of its own co-activator, the transcription co-activator PGC1- $\alpha$ (PPAR $\gamma$ coactivator 1- $\alpha$ ) through a PPAR-response element in the PGC1- $\alpha$ promoter [98]. Accordingly, upon activation by a PPAR agonist, the PPAR-PGC1- $\alpha$ system forms a feedforward loop to transcriptionally amplify mitochondrial energy production while promoting mitochondrial biogenesis. Consistent with this, administration of bezafibrate was shown to increase PGC1- $\alpha$ expression and stimulate mitochondrial biogenesis and antioxidant defense in the striata of mice modeling Huntington's disease. These metabolic changes were associated with improvements in motor coordination, motor deficits, and survival [97].

PPARs regulate inflammatory pathways by controlling gene expression of key transcription factors such as NF-KB or cyclooxygenase [30,99]. Activation of PPAR $\alpha$ and PPAR $\gamma$ by selective agonists has been reported to exert neuro-protective effects by reducing oxidative stress and neuroinflammation, which are processes involved in ASD pathophysiology.

Since mitochondrial dysfunction is considered as a possible determining factor in the pathogenesis of neuropsychiatric diseases including ASD, some authors have explored the potential of fibrates or TZD in animal models of these disorders $[30,84,99]$. Most recently bezafibrate, a pan-PPAR agonist, has been tested for bipolar depression in a proof-of-concept clinical trial (NCT02481245) [83].

\subsection{Preliminary Evidence of Natural FAO Activator Resveratrol in ASD}

An increasing number of studies have been focusing on the effects of RSV in animal models of ASD. Prenatal exposure to RSV attenuates the ASD-like behavior in the model induced by prenatal exposure to valproic acid (VPA), although the molecular mechanisms mediating the effects at the cellular level are still largely undiscovered [42]. RSV lessens the effects of VPA-induced depletion of GABAergic parvalbumin (PV+) neurons in sensory brain regions and in the amygdala [44]. Recent evidence shows that RSV exerts epigenetic effects which counteract the effects of environmental factors such as VPA on molecular targets of ASD. MicroRNAs (miRNAs) are a group of small noncoding RNA molecules which can regulate gene expression at the post-transcriptional level. Dysregulation of miRNA may lead to abnormal DNA methylation and a change in the expression of ASD-related genes. The study of miRNA has added information on ASD pathogenesis and might become helpful to better discriminate between different disease subgroups. In this regard, we recently validated serum miR-140-3p as significantly upregulated in ASD patients compared to healthy controls and we found that miR-140-3p may discriminate against patients with a unique ASD diagnosis from those with ASD associated to a comorbid disorder (ASD and Tourette syndrome) [100]. Interestingly, RSV-dependent amelioration of social behavior in a VPA model runs parallel to a decrease of miRNA miR134-5p and miR138-5p that are also upregulated in individuals with ASD [45].

The putative mechanisms of RSV effectiveness in models include regulation of abnormal neuroimmune response in ASD. RSV-treated BTBR mice, a mouse model largely validated for ASD, had significant decrease in IL-6, TNF- $\alpha$, IFN- $\gamma$, and STAT3 in CD4+ spleen cells when compared to BTBR control mice. RSV treatment also decreased IL-6, TNF- $\alpha$, IFN- $\gamma$, JAK1, and STAT3 mRNA expression levels in the brain tissue when compared to BTBR control mice [101].

Interestingly, RSV reversed the effects of prenatal progestin-exposure-induced ASD-like behavior through the activation of Estrogen Receptor $\beta(E R \beta)$ and its target genes in the amygdala. As a consequence, RSV significantly improved ASD-like behavior in the model. Behavioral amelioration was associated with improved mitochondrial function and FAO flux, demonstrated by measuring palmitate oxidation rate in vivo [46]. In line with evidence in experimental models of ASD, the effects of RSV in fueling mtFAO have been demonstrated in cultured human fibroblasts of patients with genetic FAO defects. RSV enhances residual CPT2 activity in fibroblasts harboring CPT2 gene mutations and 
restores normal FAO rates [102]. Similar effects were also documented in fibroblasts from patients with VLCAD deficiency, suggesting that RSV can improve mtFAO in human FAO-deficient cells [103].

Currently, the molecular mechanisms of RSV-induced FAO regulation are not completely understood. It has been shown that RSV increases the activity and gene expression of sirtuin 1 (SIRT1), associated with an increase in CPT1 mRNA, encoding the rate-limiting enzyme of mtFAO. Moreover, SIRT1 activation could result in PGC- $1 \alpha$ activation, and in the transcriptional co-activation of nuclear and mitochondrial genes encoding for proteins involved in mitochondrial biogenesis, oxidative phosphorylation, and energy production. Finally, post-translational SIRT1 activation by AMP-activated protein kinase could further enhance FAO and mitochondrial biogenesis [103,104].

\subsection{PPAR $\alpha$ and Autism Spectrum Disorder}

The implication of PPARs in lipid homeostasis and the greater risk for obesity and dyslipidemia in ASD compared to the general population [105], suggest a role for PPAR $\alpha$ in metabolic dysregulation in patients with ASD. PPAR $\alpha$ expression and function have been explored in various preclinical models of ASD. PPAR $\alpha$ expression is depressed in the frontal cortex of the VPA rodent model of ASD (VPA-model) [106], whereas the administration of palmitoylethanolamide (PEA), an endogenous lipid agonist of PPAR $\alpha$, reduced autistic behavior in the VPA-model of ASD [107]. The effects of PPAR $\alpha$ activation were analyzed in a BTBR T+tf/J (BTBR) mouse model. PPAR $\alpha$ activation associated with selective PPAR $\alpha$ agonists [31] and with PEA supplementation [108] reduced the repetitive behavior and stereotypes in the BTBR mouse model.

PPAR $\alpha$ deficient mice have a distinct cognitive and behavioral phenotype characterized by reduced spatial information processing and cognitive flexibility, along with repetitive/perseverative behavior reminiscent of that seen in preclinical models of ASD. Morphological and functional analysis in PPAR $\alpha$ deficient mice showed an impairment of parvalbumin-positive GABA-ergic interneurons in the frontal cortex and in the hippocampus, resulting in cortical excitation [31]. As expected, PEA administration failed in inducing its effect to ameliorate stereotyped behaviors in PPAR $\alpha$ knockout mice [108]. Based on this evidence, PEA was used as an adjunctive therapy to treat irritability and hyperactivity symptoms in children with ASD receiving risperidone, with significant effects compared to risperidone plus placebo [109]. These findings collectively link PPAR $\alpha$ activation with improved behavioral phenotype in ASD preclinical models, and support the role of PPAR $\alpha$ as therapeutic target for drug development in ASD.

\subsection{PPAR $\gamma$ and Autism Spectrum Disorders}

TZD are PPAR $\gamma$ agonists that act as anti-diabetic drugs due to insulin-sensitizing effects. TZD molecules share anti-inflammatory properties and have been used in a variety of inflammatory diseases such as atherosclerosis, psoriasis, and inflammatory bowel disease [29]. Pioglitazone is a TZD approved and commercialized for treatment of type I diabetes, also in adolescence [110]. Pioglitazone reduces inflammatory glia activation and improves glucose utilization and lactate production in brain glial cells [111]. The use of pioglitazone in ASD patients has been considered, based on evidence that links ASD to immune dysregulation [109], occurrence of autoimmune diseases in children with ASD [110], and neuroinflammation [112]. In particular, altered immune response in patients with ASD include abnormal T lymphocyte function, increased cytokines of Th2 and Th1 arms of the immune response, and neuroinflammatory changes seen in autoptic brains consistent with microglia and astroglia activation $[113,114]$. Evidence of the intrinsic relation between neuroinflammation and ASD have been extensively reviewed [115].

Based on neuroprotective and anti-inflammatory properties, in 2007 pioglitazone was first used in a clinical trial including twenty-five children and adolescents with age ranging from 3 to 17 years. Participants showed high prevalence of auto-immune comorbidities and allergic diseases. In this cohort of patients with ASD, pioglitazone treatment at the dosage 30-60 mg per day for 3-4 months was effective in amelioration of social behavior by reducing irritability, lethargy, stereotypy and 
hyperactivity measured using the Aberrant Behavior Checklist, particularly in younger patients. No adverse effects were recorded in the study period [32]. Later on, pioglitazone was studied as a treatment adjunct to risperidone in children with ASD aged 4-12 years. A 10-week randomized, double-blind, placebo-controlled trial supported the safety profile and its role in controlling behavioral symptoms of ASD [33]. The efficacy of pioglitazione in ASD was related to different effects of PPAR $\gamma$ activation, such as reduction of brain glia-mediated inflammatory response, improvement of brain mitochondrial function, and activation of the met proto-oncogene (hepatocyte growth factor receptor) (MET) signal transduction pathway [116]. Although safety profiles of TZD were documented in young patients with type 1 diabetes [110], further studies are required to understand the effects on behavior and long-term safety of TZD in children with ASD. Novel approaches using natural FAO activators like RSV are particularly appealing, due to their proven application for correction of CPT2and VLCAD-deficiency in patient cells [103,117].

\section{Concluding Remarks}

There are currently no US Food and Drug Administration-approved drugs for the core symptoms of ASD, although several agents demonstrate promise for the treatment of social deficit symptoms [118]. ASD is a highly heterogeneous condition with variable underlying mechanisms. Recognition of specific classes of ASD patients by biological markers has been considering effective for better understanding molecular mechanisms and to guide tailored therapeutic strategies. If the exact nature of mitochondrial dysfunction(s) in ASD patients, and its tissue distribution, remain unclear as yet, it can nevertheless be suggested that pharmacotherapy targeting the FAO or RC might be quite relevant to test.

During the last decade, a large number of studies have been dedicated to the characterization of various biological properties of RSV, and it is now known that improvement of mitochondrial functions is a key element that accounts for RSV's beneficial effects. These observations suggest possible helpful applications of RSV in many diseases such as cancer, cardiovascular, metabolic (diabetes, obesity), or neurodegenerative disorders (Alzheimer and Parkinson) [41]. Valuable in vivo data have been gathered, supporting a good safety profile and tolerability of RSV in humans [119].

Considering all available data, we suggest an additional biological involvement of RSV in the treatment of ASD via regulation of mtFAO and energy homeostasis (Figure 1). Future studies in this domain might be directed toward (1) testing the occurrence of allelic variations responsible for heat inactivation of CPT2 and other pivotal components of ATP generation through mtFAO. This topic is particularly important in children with regressive ASD apparently related to infections and high-fever episodes; (2) ex-vivo approaches in patient cells might be helpful to understand the effectiveness of RSV and synthetic PPAR activators in improving energy metabolism in ASD; (3) further studies using ASD models including a PPA rodent model could help to clarify whether activation of metabolic FAO using RSV and correction of related metabolic changes, such as abnormal acyl-carnitine profiles, run parallel to behavioral amelioration. Naturally occurring activators of FAO like RSV and synthetic PPARs agonists with proven activity in regulating FAO currently used in clinical practice might thus become available for clinical trials in patients with ASD. 

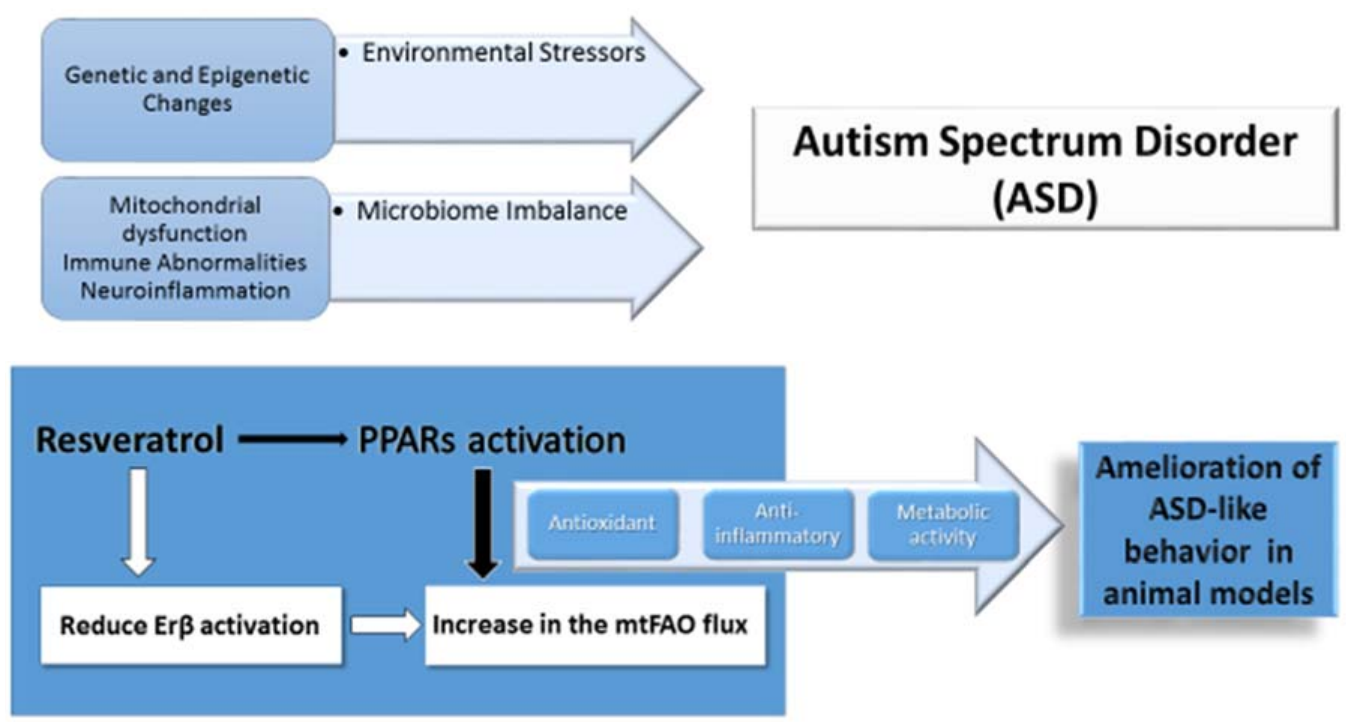

Figure 1. Pathogenetic mechanisms of autism spectrum disorder (ASD) and related resveratrol (RSV) actions with potential therapeutic effects proven in ASD animal models.

Author Contributions: Conceptualization, R.B., R.R. and J.B.; writing—original draft preparation R.B., J.B., T.G., M.G.; writing — review and editing, R.E.F.

Funding: This research received no external funding.

Conflicts of Interest: The authors declare no conflict of interest.

\section{Abbreviations}

$\begin{array}{ll}\text { ASD } & \text { autism spectrum disorder } \\ \text { CPT } & \text { carnitine palmitoyl transferase } \\ \text { CNS } & \text { central nervous system } \\ \text { ER } \beta & \text { Estrogen Receptor } \beta \\ \text { ESI-MS/MS } & \text { Electrospray ionization tandem mass spectrometry } \\ \text { FAO } & \text { fatty acid oxidation } \\ \text { IAE } & \text { influenza associated encephalopathy } \\ \text { IEM } & \text { inborn errors of metabolism } \\ \text { LCFA } & \text { long-chain fatty acid } \\ \text { LCHAD } & \text { long chain 3-hydroxyacyl-CoA dehydrogenase } \\ \text { MCAD } & \text { medium chain acyl-CoA dehydrogenase } \\ \text { MET } & \text { met proto-oncogene } \\ \text { miRNA } & \text { microRNA } \\ \text { mtFAO } & \text { mitochondrial long-chain fatty acid oxidation } \\ \text { NSC } & \text { neural stem cells } \\ \text { PPAR } & \text { peroxisome proliferator-activated receptors } \\ \text { PGC-1 } \alpha & \text { PPAR } \gamma \text { coactivator 1- } \alpha \\ \text { PA } & \text { propionic acidemia } \\ \text { PEA } & \text { palmitoylethanolamide } \\ \text { PPA } & \text { propionic acid } \\ \text { RC } & \text { respiratory chain } \\ \text { RSV } & \text { resveratrol } \\ \text { SCAD } & \text { short chain Acyl-CoA dehydrogenase } \\ \text { SIRT1 } & \text { sirtuin 1 } \\ \text { TCA } & \text { tricarboxylic acid } \\ \text { TZD } & \text { thiazolidinediones } \\ \text { VLCAD } & \text { very long chain acyl-CoA dehydrogenase }\end{array}$




\section{References}

1. American Psychiatric Association. Desk Reference to the Diagnostic Criteria from DSM-5 ${ }^{\mathrm{TM}}$, 5th ed.; American Psychiatric Association: Washington, DC, USA, 2013; ISBN 9780890425633.

2. Baio, J.; Wiggins, L.; Christensen, D.L.; Maenner, M.J.; Daniels, J.; Warren, Z.; Kurzius-Spencer, M.; Zahorodny, W.; Robinson Rosenberg, C.; White, T.; et al. Prevalence of Autism Spectrum Disorder among Children Aged 8 Years-Autism and Developmental Disabilities Monitoring Network, 11 Sites, United States, 2014. MMWR Surveill. Summ. 2018, 67, 1-23. [CrossRef]

3. Rossignol, D.A.; Frye, R.E. A review of research trends in physiological abnormalities in autism spectrum disorders: Immune dysregulation, inflammation, oxidative stress, mitochondrial dysfunction and environmental toxicant exposures. Mol. Psychiatry 2012, 17, 389-401. [CrossRef] [PubMed]

4. Barone, R.; Sturiale, L.; Fiumara, A.; Palmigiano, A.; Bua, R.O.; Rizzo, R.; Zappia, M.; Garozzo, D. CSF $\mathrm{N}$-glycan profile reveals sialylation deficiency in a patient with GM2 gangliosidosis presenting as childhood disintegrative disorder. Autism Res. 2016, 9, 423-428. [CrossRef] [PubMed]

5. Barone, R.; Pellico, A.; Pittalà, A.; Gasperini, S. Neurobehavioral phenotypes of neuronopathic mucopolysaccharidoses. Ital. J. Pediatr. 2018, 44, 121. [CrossRef] [PubMed]

6. Kiykim, E.; Zeybek, C.A.; Zubarioglu, T.; Cansever, S.; Yalcinkaya, C.; Soyucen, E.; Aydin, A. Inborn metabolic disorders in Turkish patients with autism spectrum disorders. Autism Res. 2016, 9, 217-223. [CrossRef] [PubMed]

7. Rose, S.; Niyazov, D.M.; Rossignol, D.A.; Goldenthal, M.; Kahler, S.G.; Frye, R.E. Clinical and Molecular Characteristics of Mitochondrial Dysfunction in Autism Spectrum Disorder. Mol. Diagn. Ther. 2018, 22, 571-593. [CrossRef]

8. Rossignol, D.A.; Frye, R.E. Mitochondrial dysfunction in autism spectrum disorders, a systematic review and meta-analysis. Mol. Psychiatry 2012, 17, 290-314. [CrossRef] [PubMed]

9. Legido, A.; Jethva, R.; Goldenthal, M.J. Mitochondrial dysfunction in autism. Semin. Pediatr. Neurol. 2013, 20, 163-175. [CrossRef]

10. Giulivi, C.; Zhang, Y.F.; Omanska-Klusek, A.; Ross-Inta, C.; Wong, S.; Hertz-Picciotto, I.; Tassone, F.; Pessah, I.N. Mitochondrial dysfunction in autism. JAMA 2010, 304, 2389-2396. [CrossRef]

11. Napoli, E.; Wong, S.; Hertz-Picciotto, I.; Giulivi, C. Deficits in bioenergetics and impaired immune response in granulocytes from children with autism. Pediatrics 2014, 133, e1405-e1410. [CrossRef]

12. Goldenthal, M.J.; Kuruvilla, T.; Damle, S.; Salganicoff, L.; Sheth, S.; Shah, N.; Marks, H.; Khurana, D.; Valencia, I.; Legido, A. Non-invasive evaluation of buccal respiratory chain enzyme dysfunction in mitochondrial disease, Comparison with studies in muscle biopsy. Mol. Genet. Metab. 2012, 105, 457-462. [CrossRef] [PubMed]

13. Goh, S.; Dong, Z.; Zhang, Y.; Di Mauro, S.; Peterson, B.S. Mitochondrial dysfunction as a neurobiological subtype of autism spectrum disorder, evidence from brain imaging. JAMA Psychiatry 2014, 71, 665-671. [CrossRef] [PubMed]

14. Olpin, S.E. Pathophysiology of fatty acid oxidation disorders and resultant phenotypic variability. J. Inherit. Metab. Dis. 2013, 36, 645-658. [CrossRef]

15. Bastin, J. Regulation of mitochondrial fatty acid $\beta$-oxidation in human, what can we learn from inborn fatty acid $\beta$-oxidation deficiencies? Biochimie 2014, 96, 113-120. [CrossRef] [PubMed]

16. Houten, S.M.; Violante, S.; Ventura, F.V.; Wanders, R.J. The biochemistry and physiology of mitochondrial fatty acid $\beta$-oxidation and its genetic disorders. Annu. Rev. Physiol. 2016, 78, 23-44. [CrossRef] [PubMed]

17. Longo, N.; Frigeni, M.; Pasquali, M. Carnitine transport and fatty acid oxidation. Biochim. Biophys. Acta 2016, 1863, 2422-2435. [CrossRef] [PubMed]

18. Brown, A.; Crowe, L.; Andresen, B.S.; Anderson, V.; Boneh, A. Neurodevelopmental profiles of children with very long chain acyl-CoA dehydrogenase deficiency diagnosed by newborn screening. Mol. Genet. Metab. 2014, 113, 278-282. [CrossRef]

19. Strandqvist, A.; Haglind, C.B.; Zetterström, R.H.; Nemeth, A.; von Döbeln, U.; Stenlid, M.H.; Nordenström, A. Neuropsychological Development in Patients with Long-Chain 3-Hydroxyacyl-CoA Dehydrogenase (LCHAD) Deficiency. JIMD Rep. 2016, 28, 75-84. [PubMed]

20. Clark-Taylor, T.; Clark-Taylor, B.E. Is autism a disorder of fatty acid metabolism? Med. Hypotheses 2004, 62, 970-975. [CrossRef] 
21. Filipek, P.A.; Juranek, J.; Nguyen, M.T.; Cummings, C.; Gargus, J.J. Relative carnitine deficiency in autism. J. Autism Dev. Disord. 2004, 34, 615-623. [CrossRef]

22. Grygiel-Górniak, B. Peroxisome proliferator-activated receptors and their ligands, nutritional and clinical implications-A review. Nutr. J. 2014, 13, 17. [CrossRef] [PubMed]

23. Nakamura, M.T.; Yudell, B.E.; Loor, J.J. Regulation of energy metabolism by long-chain fatty acids. Prog. Lipid Res. 2014, 53, 124-144. [CrossRef]

24. Kersten, S. Integrated physiology and systems biology of PPAR $\alpha$. Mol. Metab. 2014, 3, 354-371. [CrossRef] [PubMed]

25. Karpe, F.; Ehrenborg, E.E. PPAR $\delta$ in humans, genetic and pharmacological evidence for a significant metabolic function. Curr. Opin. Lipidol. 2009, 20,333-336. [CrossRef] [PubMed]

26. Palomer, X.; Barroso, E.; Zarei, M.; Botteri, G.; Vázquez-Carrera, M. PPAR $\beta / \delta$ and lipid metabolism in the heart. Biochim. Biophys. Acta 2016, 1861, 1569-1578. [CrossRef] [PubMed]

27. Ehrenborg, E.; Krook, A. Regulation of skeletal muscle physiology and metabolism by peroxisome proliferator-activated receptor $\delta$. Pharmacol. Rev. 2009, 61, 373-393. [CrossRef]

28. Tan, N.S.; Vázquez-Carrera, M.; Montagner, A.; Sng, M.K.; Guillou, H.; Wahli, W. Transcriptional control of physiological and pathological processes by the nuclear receptor PPARß/ס. Prog. Lipid Res. 2016, 64, 98-122. [CrossRef] [PubMed]

29. Tontonoz, P.; Spiegelman, B.M. Fat and beyond, the diverse biology of PPAR $\gamma$. Annu. Rev. Biochem. 2008, 77, 289-312. [CrossRef]

30. Agarwal, S.; Yadav, A.; Chaturvedi, R.K. Peroxisome proliferator-activated receptors (PPARs) as therapeutic target in neurodegenerative disorders. Biochem. Biophys. Res. Commun. 2017, 483, 1166-1177. [CrossRef]

31. D’Agostino, G.; Cristiano, C.; Lyons, D.J.; Citraro, R.; Russo, E.; Avagliano, C.; Russo, R.; Raso, G.M.; Meli, R.; De Sarro, G.; et al. Peroxisome proliferator-activated receptor $\alpha$ plays a crucial role in behavioral repetition and cognitive flexibility in mice. Mol. Metab. 2015, 4, 528-536. [CrossRef] [PubMed]

32. Boris, M.; Kaiser, C.C.; Goldblatt, A.; Elice, M.W.; Edelson, S.M.; Adams, J.B.; Feinstein, D.L. Effect of pioglitazone treatment on behavioral symptoms in autistic children. J. Neuroinflamm. 2007, 4, 3. [CrossRef] [PubMed]

33. Ghaleiha, A.; Rasa, S.M.; Nikoo, M.; Farokhnia, M.; Mohammadi, M.R.; Akhondzadeh, S. A pilot double-blind placebo-controlled trial of pioglitazone as adjunctive treatment to risperidone, effects on aberrant behavior in children with autism. Psychiatry Res. 2015, 229, 181-187. [CrossRef] [PubMed]

34. Wang, L.; Waltenberger, B.; Pferschy-Wenzig, E.M.; Blunder, M.; Liu, X.; Malainer, C.; Blazevic, T.; Schwaiger, S.; Rollinger, J.M.; Heiss, E.H.; et al. Natural product agonists of peroxisome proliferator-activated receptor gamma (PPAR $\gamma$ ), a review. Biochem. Pharmacol. 2014, 92, 73-89. [CrossRef] [PubMed]

35. Nakata, R.; Takahashi, S.; Inoue, H. Recent advances in the study on resveratrol. Biol. Pharm. Bull. 2012, 35, 273-279. [CrossRef]

36. Wąsik, A.; Antkiewicz-Michaluk, L. The mechanism of neuroprotective action of natural compounds. Pharmacol. Rep. 2017, 69, 851-860. [CrossRef] [PubMed]

37. Malaguarnera, G.; Pennisi, M.; Bertino, G.; Motta, M.; Borzì, A.M.; Vicari, E.; Bella, R.; Drago, F.; Malaguarnera, M. Resveratrol in patients with minimal hepatic encephalopathy. Nutrients 2018, 10, 329. [CrossRef] [PubMed]

38. Baur, J.A.; Sinclair, D.A. Therapeutic potential of resveratrol, the in vivo evidence. Nat. Rev. Drug. Discov. 2006, 5, 493-506. [CrossRef] [PubMed]

39. Lagouge, M.; Argmann, C.; Gerhart-Hines, Z.; Meziane, H.; Lerin, C.; Daussin, F.; Messadeq, N.; Milne, J.; Lambert, P.; Elliott, P.; et al. Resveratrol improves mitochondrial function and protects against metabolic disease by activating SIRT1 and PGC-1alpha. Cell 2006, 127, 1109-1122. [CrossRef] [PubMed]

40. Tomé-Carneiro, J.; Larrosa, M.; González-Sarrías, A.; Tomás-Barberán, F.A.; García-Conesa, M.T.; Espín, J.C. Resveratrol and clinical trials, the crossroad from in vitro studies to human evidence. Curr. Pharm. Des. 2013, 19, 6064-6093. [CrossRef] [PubMed]

41. Park, E.J.; Pezzuto, J.M. The pharmacology of resveratrol in animals and humans. Biochim. Biophys. Acta 2015, 1852, 1071-1113. [CrossRef]

42. Bambini-Junior, V.; Zanatta, G.; Della Flora Nunes, G.; Mueller de Melo, G.; Michels, M.; Fontes-Dutra, M.; Nogueira Freire, V.; Riesgo, R.; Gottfried, C. Resveratrol prevents social deficits in animal model of autism induced by valproic acid. Neurosci. Lett. 2014, 583, 176-181. [CrossRef] [PubMed] 
43. Bakheet, S.A.; Alzahrani, M.Z.; Nadeem, A.; Ansari, M.A.; Zoheir, K.M.A.; Attia, S.M.; Al-Ayadhi, L.Y.; Ahmad, S.F. Resveratrol treatment attenuates chemokine receptor expression in the BTBR T+tf/J mouse model of autism. Mol. Cell. Neurosci. 2016, 77, 1-10. [CrossRef] [PubMed]

44. Fontes-Dutra, M.; Santos-Terra, J.; Deckmann, I.; Brum Schwingel, G.; Della Flora Nunes, G.; Hirsch, M.M.; Bauer-Negrini, G.; Riesgo, R.S.; Bambini-Júnior, V.; Hedin-Pereira, C.; et al. Resveratrol prevents cellular and behavioral sensory alterations in the animal model of autism induced by valproic acid. Front. Synaptic Neurosci. 2018, 10, 9. [CrossRef] [PubMed]

45. Hirsch, M.M.; Deckmann, I.; Fontes-Dutra, M.; Bauer-Negrini, G.; Della Flora Nunes, G.; Nunes, W.; Rabelo, B.; Riesgo, R.; Margis, R.; Bambini-Junior, V.; et al. Behavioral alterations in autism model induced by valproic acid and translational analysis of circulating microRNA. Food Chem. Toxicol. 2018, 115, 336-343. [CrossRef] [PubMed]

46. Xie, W.; Ge, X.; Li, L.; Yao, A.; Wang, X.; Li, M.; Gong, X.; Chu, Z.; Lu, Z.; Huang, X.; et al. Resveratrol ameliorates prenatal progestin exposure-induced autism-like behavior through ER $\beta$ activation. Mol. Autism 2018, 9, 43. [CrossRef]

47. Zhao, S.; Xu, W.; Jiang, W.; Yu, W.; Lin, Y.; Zhang, T.; Yao, J.; Zhou, L.; Zeng, Y.; Li, H.; et al. Regulation of cellular metabolism by protein lysine acetylation. Science 2010, 327, 1000-1004. [CrossRef]

48. McDonnell, E.; Crown, S.B.; Fox, D.B.; Kitir, B.; Ilkayeva, O.R.; Olsen, C.A.; Grimsrud, P.A.; Hirschey, M.D. Lipids reprogram metabolism to become a major carbon source for histone acetylation. Cell Rep. 2016, 17, 1463-1472. [CrossRef] [PubMed]

49. Pougovkina, O.; te Brinke, H.; Ofman, R.; van Cruchten, A.G.; Kulik, W.; Wanders, R.J.; Houten, S.M.; de Boer, V.C. Mitochondrial protein acetylation is driven by acetyl-CoA from fatty acid oxidation. Hum. Mol. Genet. 2014, 23, 3513-3522. [CrossRef]

50. Reid, M.A.; Dai, Z.; Locasale, J.W. The impact of cellular metabolism on chromatin dynamics and epigenetics. Nat. Cell. Biol. 2017, 19, 1298-1306. [CrossRef]

51. Waye, M.M.Y.; Cheng, H.Y. Genetics and epigenetics of autism: A Review. Psychiatry Clin. Neurosci. 2018, 72, 228-244. [CrossRef] [PubMed]

52. Sun, W.; Poschmann, J.; Cruz-Herrera Del Rosario, R.; Parikshak, N.N.; Hajan, H.S.; Kumar, V.; Ramasamy, R.; Belgard, T.G.; Elanggovan, B.; Wong, C.C.Y.; et al. Histone Acetylome-wide Association Study of Autism Spectrum Disorder. Cell 2016, 167, 1385-1397. [CrossRef] [PubMed]

53. Wajner, M.; Amaral, A.U. Mitochondrial dysfunction in fatty acid oxidation disorders, insights from human and animal studies. Biosci. Rep. 2016, 36, e00281. [CrossRef] [PubMed]

54. Celestino-Soper, P.B.; Violante, S.; Crawford, E.L.; Luo, R.; Lionel, A.C.; Delaby, E.; Cai, G.; Sadikovic, B.; Lee, K.; Lo, C.; et al. A common X-linked inborn error of carnitine biosynthesis may be a risk factor for nondysmorphic autism. Proc. Natl. Acad. Sci. USA 2012, 109, 7974-7981. [CrossRef]

55. Schönfeld, P.; Reiser, G. Why does brain metabolism not favor burning of fatty acids to provide energy? Reflections on disadvantages of the use of free fatty acids as fuel for brain. J. Cereb. Blood Flow Metab. 2013, 33, 1493-1499. [CrossRef] [PubMed]

56. Panov, A.; Orynbayeva, Z.; Vavilin, V.; Lyakhovich, V. Fatty acids in energy metabolism of the central nervous system. Biomed. Res. Int. 2014, 2014, 472459. [CrossRef] [PubMed]

57. Jernberg, J.N.; Bowman, C.E.; Wolfgang, M.J.; Scafidi, S. Developmental regulation and localization of carnitine palmitoyltransferases (CPTs) in rat brain. J. Neurochem. 2017, 142, 407-419. [CrossRef] [PubMed]

58. Xie, Z.; Jones, A.; Deeney, J.T.; Hur, S.K.; Bankaitis, V.A. Inborn errors of long-chain fatty acid $\beta$-oxidation link neural stem cell self-renewal to autism. Cell Rep. 2016, 14, 991-999. [CrossRef] [PubMed]

59. Knobloch, M.; Pilz, G.A.; Ghesquière, B.; Kovacs, W.J.; Wegleiter, T.; Moore, D.L.; Hruzova, M.; Zamboni, N.; Carmeliet, P.; Jessberger, S. Fatty acid oxidation-dependent metabolic shift regulates adult neural stem cell activity. Cell Rep. 2017, 20, 2144-2155. [CrossRef] [PubMed]

60. Bonnefont, J.P.; Djouadi, F.; Prip-Buus, C.; Gobin, S.; Munnich, A.; Bastin, J. Carnitine palmitoyltransferases 1 and 2, biochemical.; molecular and medical aspects. Mol. Asp. Med. 2004, 25, 495-520. [CrossRef] [PubMed]

61. Tein, I. Impact of fatty acid oxidation disorders in child neurology, from Reye syndrome to Pandora's box. Dev. Med. Child Neurol. 2015, 57, 304-306. [CrossRef]

62. Ozonoff, S.; Williams, B.J.; Landa, R. Parental report of the early development of children with regressive autism. The delays-plus-regression phenotype. Autism 2005, 9, 461-486. [CrossRef] [PubMed] 
63. Longo, N.; Amat di San Filippo, C.; Pasquali, M. Disorders of carnitine transport and the carnitine cycle. Am. J. Med. Genet. 2006, 142C, 77-85. [CrossRef] [PubMed]

64. Yao, M.; Yao, D.; Yamaguchi, M.; Chida, J.; Yao, D.; Kido, H. Bezafibrate upregulates carnitine palmitoyltransferase II expression and promotes mitochondrial energy crisis dissipation in fibroblasts of patients with influenza-associated encephalopathy. Mol. Genet. Metab. 2011, 104, 265-272. [CrossRef] [PubMed]

65. El-Ansary, A.K.; Bacha, A.G.; Al-Ayahdi, L.Y. Plasma fatty acids as diagnostic markers in autistic patients from Saudi Arabia. Lipids Health Dis. 2011, 10, 62. [CrossRef] [PubMed]

66. Pastural, E.; Ritchie, S.; Lu, Y.; Jin, W.; Kavianpour, A.; Khine Su-Myat, K.; Heath, D.; Wood, P.L.; Fisk, M.; Goodenowe, D.B. Novel plasma phospholipid biomarkers of autism, mitochondrial dysfunction as a putative causative mechanism. Prostaglandins Leukot. Essent. Fat. Acids 2009, 81, 253-264. [CrossRef] [PubMed]

67. Lai, J.C.; Liang, B.B.; Jarvi, E.J.; Cooper, A.J.; Lu, D.R. Differential effects of fatty acyl coenzyme A derivatives on citrate synthase and glutamate dehydrogenase. Res. Commun. Chem. Pathol. Pharmacol. 1993, 82, 331-338. [PubMed]

68. Ventura, F.V.; Ruiter, J.P.; Ijlst, L.; de Almeida, I.T.; Wanders, R.J. Inhibitory effect of 3-hydroxyacyl-CoAs and other long chain fatty acid beta-oxidation intermediates on mitochondrial oxidative phosphorylation. J. Inherit. Metab. Dis. 1996, 19, 161-164. [CrossRef] [PubMed]

69. Frye, R.E.; Melnyk, S.; MacFabe, D.F. Unique acyl-carnitine profiles are potential biomarkers for acquired mitochondrial disease in autism spectrum disorder. Transl. Psychiatry 2013, 3, e220. [CrossRef]

70. Barone, R.; Alaimo, S.; Messina, M.; Pulvirenti, A.; Bastin, J.; MIMIC-Autism group; Ferro, A.; Frye, R.E.; Rizzo, R. A subset of patients with Autism Spectrum Disorders show a distinctive metabolic profile by dried blood spot analyses. Front. Psychiatry 2018, 9, 636. [CrossRef] [PubMed]

71. Zakaria, R.; Allen, K.J.; Koplin, J.J.; Roche, P.; Greaves, R.F. Advantages and Challenges of Dried Blood Spot Analysis by Mass Spectrometry Across the Total Testing Process. EJIFCC 2016, 27, 288-317.

72. Shultz, S.R.; MacFabe, D.F.; Ossenkopp, K.P.; Scratch, S.; Whelan, J.; Taylor, R.; Cain, D.P. Intracerebroventricular injection of propionic acid, an enteric bacterial metabolic end-product, impairs social behavior in the rat, implications for an animal model of autism. Neuropharmacology 2008, 54, 901-911. [CrossRef] [PubMed]

73. Thomas, R.H.; Foley, K.A.; Mepham, J.R.; Tichenoff, L.J.; Possmayer, F.; MacFabe, D.F. Altered brain phospholipid and acylcarnitine profiles in propionic acid infused rodents, further development of a potential model of autism spectrum disorders. J. Neurochem. 2010, 113, 515-529. [CrossRef] [PubMed]

74. Rose, S.; Bennuri, S.C.; Davis, J.E.; Wynne, R.; Slattery, J.C.; Tippett, M.; Delhey, L.; Melnyk, S.; Kahler, S.G.; MacFabe, D.F.; et al. Butyrate enhances mitochondrial function during oxidative stress in cell lines from boys with autism. Transl. Psychiatry 2018, 2, 42. [CrossRef]

75. Frye, R.E.; Rose, S.; Chacko, J.; Wynne, R.; Bennuri, S.C.; Slattery, J.C.; Tippett, M.; Delhey, L.; Melnyk, S.; Kahler, S.G.; et al. Modulation of mitochondrial function by the microbiome metabolite propionic acid in autism and control cell lines. Transl. Psychiatry 2016, 25, e927. [CrossRef] [PubMed]

76. Witters, P.; Debbold, E.; Crivelly, K.; Vande Kerckhove, K.; Corthouts, K.; Debbold, B.; Andersson, H.; Vannieuwenborg, L.; Geuens, S.; Baumgartner, M.; et al. Autism in patients with propionic acidemia. Mol. Genet. Metab. 2016, 119, 317-321. [CrossRef] [PubMed]

77. Griffiths, K.K.; Levy, R.J. Evidence of mitochondrial dysfunction in autism, biochemical links, genetic-based associations, and non-energy-related mechanisms. Oxid. Med. Cell. Longev. 2017, 2017, 4314025. [CrossRef] [PubMed]

78. Hollis, F.; Kanellopoulos, A.K.; Bagni, C. Mitochondrial dysfunction in autism spectrum disorder, clinical features and perspectives. Curr. Opin. Neurobiol. 2017, 45, 178-187. [CrossRef] [PubMed]

79. Pei, L.; Wallace, D.C. Mitochondrial etiology of neuropsychiatric disorders. Biol. Psychiatry 2018, 83, 722-730. [CrossRef]

80. Ben-Shachar, D.; Ene, H.M. Mitochondrial targeted therapies, where do we stand in mental disorders? Biol. Psychiatry 2018, 83, 770-779. [CrossRef]

81. Mandard, S.; Müller, M.; Kersten, S. Peroxisome proliferator-activated receptor $\alpha$ target genes. Cell. Mol. Life Sci. 2004, 61, 393-416. [CrossRef]

82. Lin, J.; Handschin, C.; Spiegelman, B.M. Metabolic control through the PGC-1 family of transcription coactivators. Cell Metab. 2005, 1, 361-370. [CrossRef] [PubMed] 
83. Nierenberg, A.A.; Ghaznavi, S.A.; Sande Mathias, I.; Ellard, K.K.; Janos, J.A.; Sylvia, L.G. peroxisome proliferator-activated receptor $\gamma$ coactivator-1 $\alpha$ as a novel target for bipolar disorder and other neuropsychiatric disorders. Biol. Psychiatry. 2018, 83, 761-769. [CrossRef]

84. Corona, J.C.; Duchen, M.R. PPAR $\gamma$ as a therapeutic target to rescue mitochondrial function in neurological disease. Free Radic. Biol. Med. 2016, 100, 153-163. [CrossRef]

85. Bugge, A.; Holst, D. PPAR agonists, - Could tissue targeting pave the way? Biochimie 2017, 136, $100-104$. [CrossRef] [PubMed]

86. Djouadi, F.; Bonnefont, J.P.; Thuillier, L.; Droin, V.; Khadom, N.; Munnich, A.; Bastin, J. Correction of fatty acid oxidation in carnitine palmitoyl transferase II deficient cultured skin fibroblasts by bezafibrate. Pediatr. Res. 2003, 54, 446-451. [CrossRef]

87. Djouadi, F.; Aubey, F.; Schlemmer, D.; Ruiter, J.P.; Wanders, R.J.; Strauss, A.W.; Bastin, J. Bezafibrate increases very-long-chain acyl-CoA dehydrogenase protein and mRNA expression in deficient fibroblasts and is a potential therapy for fatty acid oxidation disorders. Hum. Mol. Genet. 2005, 14, 2695-2703. [CrossRef]

88. Bastin, J.; Aubey, F.; Rötig, A.; Munnich, A.; Djouadi, F. Activation of peroxisome proliferator activated receptor pathway stimulates the mitochondrial respiratory chain and can correct deficiencies in patients' cells lacking its components. J. Clin. Endocrinol. Metab. 2008, 93, 1433-1441. [CrossRef]

89. Gobin-Limballe, F.; Djouadi, F.; Aubey, S.; Olpin, B.S.; Andresen, S.; Yamaguchi, H.; Mandel, H.; Fukao, T.; Ruiter, J.P.; Wanders, R.J.; et al. Genetic basis for correction of very long chain acyl-CoA dehydrogenase deficiency by bezafibrate in patient fibroblasts, towards a genotype-based therapy. Am. J. Hum. Genet. 2007, 81, 1133-1143. [CrossRef]

90. Yamada, K.; Kobayashi, H.; Bo, R.; Purevsuren, J.; Mushimoto, Y.; Takahashi, T.; Hasegawa, Y.; Taketani, T.; Fukuda, S.; Yamaguchi, S. Efficacy of bezafibrate on fibroblasts of glutaric acidemia type II patients evaluated using an in vitro probe acylcarnitine assay. Brain Dev. 2017, 39, 48-57. [CrossRef] [PubMed]

91. Bonnefont, J.P.; Bastin, J.; Behin, A.; Djouadi, F. Bezafibrate for an inborn mitochondrial beta-oxidation defect. N. Engl. J. Med. 2009, 360, 838-840. [CrossRef] [PubMed]

92. Bonnefont, J.P.; Bastin, J.; Laforêt, P.; Aubey, F.; Mogenet, A.; Romano, S.; Ricquier, D.; Gobin-Limballe, S.; Vassault, A.; Behin, A.; et al. Long term follow-up of bezafibrate treatment in the myopathic form of Carnitine-PalmitoylTransferase 2 deficiency. Clin. Pharm. Ther. 2010, 88, 101-108. [CrossRef]

93. Newcastle University; Newcastle-upon-Tyne Hospitals NHS Trust. A Study of Bezafibrate in Mitochondrial Myopathy. Available online: https://clinicaltrials.gov/ct2/show/NCT02398201 (accessed on 16 February 2019).

94. Morishima, T.; Togashi, T.; Yokota, S.; Okuno, Y.; Miyazaki, C.; Tashiro, M.; Okabe, N. Encephalitis and encephalopathy associated with an influenza epidemic in Japan. Clin. Infect. Dis. 2002, 35, 512-517. [CrossRef]

95. Torres-Espínola, F.J.; Altmäe, S.; Segura, M.T.; Jerez, A.; Anjos, T.; Chisaguano, M.; Carmen López-Sabater, M.; Entrala, C.; Alvarez, J.C.; Agil, A.; et al. Maternal PPARG Pro12Ala polymorphism is associated with infant's neurodevelopmental outcomes at 18 months of age. Early Hum. Dev. 2015, 91, 457-462. [CrossRef]

96. Racke, M.K.; Drew, P.D. PPARs in Neuroinflammation. PPAR Res. 2008, 2008, 638356. [CrossRef]

97. Chandra, A.; Sharma, A.; Calingasan, N.Y.; White, J.M.; Shurubor, Y.; Yang, X.W.; Beal, M.F.; Johri, A. Enhanced mitochondrial biogenesis ameliorates disease phenotype in a full-length mouse model of Huntington's disease. Hum. Mol. Genet. 2016, 25, 2269-2282. [CrossRef]

98. Hondares, E.; Pineda-Torra, I.; Iglesias, R.; Staels, B.; Villarroya, F.; Giralt, M. PPARdelta, but not PPARalpha, activates PGC-1alpha gene transcription in muscle. Biochem. Biophys. Res. Commun. 2007, 354, 1021-1027. [CrossRef] [PubMed]

99. Aleshin, S.; Reiser, G. Role of the peroxisome proliferator-activated receptors (PPAR) $-\alpha, \beta / \delta$ and $\gamma$ triad in regulation of reactive oxygen species signaling in brain. Biol. Chem. 2013, 394, 1553-1570. [CrossRef]

100. Cirnigliaro, M.; Barbagallo, C.; Gulisano, M.; Domini, C.N.; Barone, R.; Barbagallo, D.; Ragusa, M.; Di Pietro, C.; Rizzo, R.; Purrello, M. Expression and Regulatory Network Analysis of miR-140-3p, a New Potential Serum Biomarker for Autism Spectrum Disorder. Front. Mol. Neurosci. 2017, 10, 250. [CrossRef]

101. Ahmad, S.F.; Ansari, M.A.; Nadeem, A.; Bakheet, S.A.; Alzahrani, M.Z.; Alshammari, M.A.; Alanazi, W.A.; Alasmari, A.F.; Attia, S.M. Resveratrol attenuates pro-inflammatory cytokines and activation of JAK1-STAT3 in BTBR T+ Itpr3tf/J autistic mice. Eur. J. Pharmacol. 2018, 829, 70-78. [CrossRef] 
102. Bastin, J.; Lopes-Costa, A.; Djouadi, F. Exposure to resveratrol triggers pharmacological correction of fatty acid utilization in human fatty acid oxidation-deficient fibroblasts. Hum. Mol. Genet. 2011, 20, 2048-2057. [CrossRef] [PubMed]

103. Aires, V.; Delmas, D.; Le Bachelier, C.; Latruffe, N.; Schlemmer, D.; Benoist, J.F.; Djouadi, F.; Bastin, J. Stilbenes and resveratrol metabolites improve mitochondrial fatty acid oxidation defects in human fibroblasts. Orphanet J. Rare Dis. 2014, 9, 79. [CrossRef] [PubMed]

104. Brenmoehl, J.; Hoeflich, A. Dual control of mitochondrial biogenesis by sirtuin 1 and sirtuin 3. Mitochondrion 2013, 13, 755-761. [CrossRef] [PubMed]

105. Zuckerman, K.E.; Hill, A.P.; Guion, K.; Voltolina, L.; Fombonne, E. Overweight and obesity, prevalence and correlates in a large clinical sample of children with autism spectrum disorder. J. Autism Dev. Disord. 2014, 44, 1708-1719. [CrossRef]

106. Kerr, D.M.; Downey, L.; Conboy, M.; Finn, D.P.; Roche, M. Alterations in the endocannabinoid system in the rat valproic acid model of autism. Behav. Brain Res. 2013, 249, 124-132. [CrossRef]

107. Bertolino, B.; Crupi, R.; Impellizzeri, D.; Bruschetta, G.; Cordaro, M.; Siracusa, R.; Esposito, E.; Cuzzocrea, S. Beneficial effects of co-ultramicronized palmitoylethanolamide/ luteolin in a mouse model of autism and in a case report of autism. CNS Neurosci. Ther. 2017, 23, 87-98. [CrossRef] [PubMed]

108. Cristiano, C.; Pirozzi, C.; Coretti, L.; Cavaliere, G.; Lama, A.; Russo, R.; Lembo, F.; Mollica, M.P.; Meli, R.; Calignano, A.; et al. Palmitoylethanolamide counteracts autistic-like behaviours in BTBR T+tf/J mice, contribution of central and peripheral mechanisms. Brain Behav. Immun. 2018, 74, 166-175. [CrossRef]

109. Khalaj, M.; Saghazadeh, A.; Shirazi, E.; Shalbafan, M.R.; Alavi, K.; Shooshtari, M.H.; Laksari, F.Y.; Hosseini, M.; Mohammadi, M.R.; Akhondzadeh, S. Palmitoylethanolamide as adjunctive therapy for autism: Efficacy and safety results from a randomized controlled trial. J. Psychiatr. Res. 2018, 103, 104-111. [CrossRef]

110. Zdravkovic, V.; Hamilton, J.K.; Daneman, D.; Cummings, E.A. Pioglitazone as adjunctive therapy in adolescents with type 1 diabetes. J. Pediatr. 2006, 149, 845-849. [CrossRef]

111. Pilipović, K.; Župan, Ž.; Dolenec, P.; Mršić-Pelčić, J.; Župan, G. A single dose of PPAR $\gamma$ agonist pioglitazone reduces cortical oxidative damage and microglial reaction following lateral fluid percussion brain injury in rats. Prog. Neuropsychopharmacol. Biol. Psychiatry 2015, 59, 8-20. [CrossRef]

112. Noriega, D.B.; Savelkoul, H.F. Immune dysregulation in autism spectrum disorder. Eur. J. Pediatr. 2014, 173, 33-43. [CrossRef]

113. Edmiston, E.; Ashwood, P.; Van De Water, J. Autoimmunity, autoantibodies, and autism spectrum disorders (ASD). Biol. Psychiatry 2017, 81, 383-390. [CrossRef] [PubMed]

114. Ashwood, P.; Krakowiak, P.; Hertz-Picciotto, I.; Hansen, R.; Pessah, I.N.; Van de Water, J. Altered T cell responses in children with autism. Brain Behav. Immun. 2011, 25, 840-849. [CrossRef] [PubMed]

115. Gładysz, D.; Krzywdzińska, A.; Hozyasz, K.K. Immune abnormalities in autism spectrum disorder-could they hold promise for causative treatment? Mol. Neurobiol. 2018, 55, 6387-6435. [CrossRef]

116. Emanuele, E.; Lossano, C.; Politi, P.; Barale, F. Pioglitazone as a therapeutic agent in autistic spectrum disorder. Med. Hypotheses 2007, 69, 699. [CrossRef] [PubMed]

117. Dembic, M.; Andersen, H.S.; Bastin, J.; Doktor, T.K.; Corydon, T.J.; Sass, J.O.; Costa, A.L.; Djouadi, F.; Andresen, B.S. Next generation sequencing of RNA reveals novel targets of resveratrol with possible implications for Canavan disease. Mol. Genet. Metab. 2018, 126, 64-76. [CrossRef] [PubMed]

118. Frye, R.F. Social Skills Deficits in Autism Spectrum Disorder: Potential Biological Origins and Progress in Developing Therapeutic Agents. CNS Drugs 2018, 32, 713-734. [CrossRef] [PubMed]

119. Patel, K.R.; Scott, E.; Brown, V.A.; Gescher, A.J.; Steward, P.W.; Brown, K. Clinical trials of resveratrol. Ann. R. Y. Acad. Sci. 2011, 1215, 161-169. [CrossRef] [PubMed]

(C) 2019 by the authors. Licensee MDPI, Basel, Switzerland. This article is an open access article distributed under the terms and conditions of the Creative Commons Attribution (CC BY) license (http://creativecommons.org/licenses/by/4.0/). 